\title{
E-Learning Readiness in Organisations - Case Healthcare
}

\author{
doi:10.3991/ijac.v2i2.908 \\ Jeanne Schreurs, Anouk Gelan and George Sammour \\ Hasselt University, Diepenbeek, Belgium
}

\begin{abstract}
E-Learning is a good opportunity for companies to up-skill their employees and to meet the demands of lifelong learning but the implementation of it needs to be well prepared and managed because it takes often high investment costs both on the financial and the organisational side. That is why it is important for a company to know if it is elearning ready. E-readiness and e-learning readiness are already well covered in literature and several theoretical models are suggested. We developed an e-learning readiness measurement instrument based on these models. We used it as a survey instrument to conclude about the e-learning readiness of Flemish hospitals.
\end{abstract}

Index Terms-e-learning, e-adoption, e-readiness, measuring e-readiness.

\section{INTRODUCTION TO THE RESEARCH OF E-LEARNING READINESS}

\section{A. E-learning and learning in a company}

E-Learning is presented as an opportunity, delivering time and location independent learning on a cost effective way. Looking at e-learning in today's organisations, it can be defined as the delivery of instructional content or learning experiences enabled by electronic technology and it is one of the major innovations that is diffusing corporate settings. The number of e-learning initiatives in corporate training scenarios is steadily increasing.

Thanks to the combination of multiple delivery media complementing each other and a blend of learning tools (real time virtual/collaboration software, self-paced webbased courses, electronic performance support systems embedded within the job-task environment, knowledge management systems), e-learning can be customised to the learning requirements and preferences of each learner [29].

In e-learning, the learners use the internet, collaborate with peers and interact with the instructor. Experienced elearners can even use technology to monitor their training and ultimately become responsible managers of their own personal and career development. However, self-directed learning requires some specific skills, such as the ability to work alone, time management skills, persistence in learning, reading ability, competence in using the computer etc. [22].

\section{B. E-learning readiness and readiness assessment}

For a successful implementation of e-learning, there are several conditions to be met. Literature on e-readiness typically focuses on different levels, namely a country, an organisation (industry, education) or an individual's level of readiness for e-learning.

The white paper, the 2003 e-Learning Readiness Rankings (Economist Intelligence Unit, in co-operation with IBM) studied 195 countries' availability to produce, use and expand internet - both formal and informal - at work, at school, in government and throughout society. Within each category (Government, Industry, Education and Society), e-readiness criteria were divided into 4 components: Connectivity, Capability, Content and Culture. Topranked countries such as Sweden, USA and South-Korea, characterize by a high degree of IT penetration (broadband connectivity, mobile-phone usage, high PC use) into all facets of daily life, strong educational systems (with a tradition in job training and support for lifelong learning), free economic markets, governments and businesses that have embraced technology on a cultural level, a high degree of partnering between e-learning producers and consumers.

In the 2003 e-Learning Readiness Rankings, Belgium was ranked rather high: 16 in 2002 and 17 in 2003, although it was ranked only 11 th out of 16 Western European countries.

Organisations operating in a specific country have to determine for themselves "how ready they are on several aspects to implement e-learning and how they can benefit from its advantages".

On the individual level, readiness includes learners' ability to adapt to technological challenges, collaborative training and synchronous as well as asynchronous selfpaced training. It also depends on their motivation and their discipline to learn in a self-driven mode and to respond to online instructions. E-readiness makes up the ematurity of the organisation, which also is represented in the readiness of learners. It includes the availability of infrastructure, clear training objectives, trainer support and guidance and knowledgeable leadership. Therefore, to successfully engage e-learning, readiness is required not only from the learner but also from the trainer and the organisation [3]. The successful implementation of elearning is a top-down process: "for an organization to be e-ready it must have management that believes in the technology and takes strategic measures to drive its adoption, implementation and usage in order to derive business benefits from the technology" (Ruikar 2006).

E-learning readiness assessment allows one to design comprehensive e-learning strategies and effectively implement ICT goals [13]. E-learning readiness should preferably be assessed before introducing e-learning. But how can we profile the e-readiness of an organisation and its collaborators? A comprehensive concept to measure 
the e-readiness of organisations is needed. Which criteria can be included?

Previously we did research on the adoption of ICT applications or the ICT maturity of the company. Models were developed to find out which barriers a company can experience when implementing an advanced and competitive system of e-learning. In the frame of the European project e-LIVE these models were put into practice in order to identify barriers for e-learning adoption [27].

In our e-learning quality management research, we developed a self assessment questionnaire to be completed by the learner having finished an e-learning course. The set of criteria were identified using the EFQM model of TQM. We believed that a subset of these criteria could be used as readiness criteria [26] and developed an e-learning readiness measurement instrument accordingly.

Organisations can use this instrument to measure their e-learning readiness and decide on implementing an elearning solution or on taking preparatory measures creating better conditions for e-learning (e.g. elaborating an elearning corporate strategy, improving PC availability and connectivity, motivating collaborators for lifelong learning and valorising it within the organisation, determining training needs of collaborators, etc.). The assessment of their e-readiness allows them to get maximum benefits from e-learning and at the same time reduce the risk of failure. e-Readiness assessments also allow educational institutions to determine which solutions cater best to the specific needs of each learning group.At a higher level, they can inspire policy makers to take appropriate policy measures and implement development plans for future elearners [13].

\section{The case of Agfa Healthcare}

Agfa healthcare is a leading provider of integrated IT solutions and state-of-the-art diagnostic imaging for hospitals and for the healthcare sector in general. Recently, Agfa healthcare started with providing e-learning services to its customers, the hospitals. All ICT solutions will be complemented with an optional e-learning component. The e-learning component can be accessed via an elearning portal of Agfa. Agfa is convinced of the advantages of using their e-learning solution for the hospitals, replacing the traditional classroom learning - but are hospitals ready to change?

In collaboration with the company Agfa healthcare, we investigated the e-learning readiness of 10 Flemish hospitals being the customers of Agfa. The mission of Agfa Healthcare is to support the transformation process to ICT solutions improving the medical care services of the hospitals.

For the analysis we first selected the relevant criteria from our e-learning readiness measurement instrument and developed a questionnaire of 80 questions that should assess the e-readiness of the hospitals in several areas.

We structured our research fitting the following set of research questions:

- How can companies and employees benefit from elearning?

- Which are the barriers to e-learning (and knowledge sharing) companies are experiencing?

- What is the situation on point of e-adoption? A model of barriers.
- What is e-learning readiness and which measurement models do exist?

- How can we develop a measurement model and measurement instrument?

- Case: The application in the healthcare sector

\section{E-LEARNING BENEFITS AND BARRIERS}

\section{A. How can companies and employees benefit from e- learning?}

Advantages such as asynchronous training, training at individual pace, just-in-time training, and costeffectiveness lure organisations to e-learning [23]. The opportunity to learn via technology presents an exciting prospect to train even learners with little previous access to computer-based training. E-learning is a good opportunity for organisations that deal with fast changing knowledge but the implementation of e-learning needs to be well prepared because it often takes high investment costs and the organisation needs to be ready for the change it brings about.

To summarize, our research has shown that a company can benefit from e-learning in the following ways:

First, employees can reach higher satisfaction, thanks to the easier access to knowledge/ training, a better career growth opportunity and employee flexibility in learning. Second, companies achieve increased innovation of the company thanks to increased sales, faster time to market as an indirect result and real-time collaboration facility. Third, a high level of operational efficiency is obtained thanks to time savings as a result of more streamlined and increased levels of training and reduced training hours. Fourth, important cost savings are created thanks to lower travel costs, infrastructure reduction, less material duplication.

A study on the adoption of e-learning for public health nurse continuous education showed an affirmative intention towards adopting e-learning as their way of continuing education [28]. Reasons for adopting e-learning include achieving lifelong learning, fulfilling personal interests, the orientation on concrete job needs, demands for information diversity, flexibility in time and space, the possibility of self-regulatory learning, cost-effectiveness, and less impact on family duties.

\section{B. Which are the barriers to e-learning (and knowledge sharing) experienced by companies?}

Several barriers were already identified to learning in general: learners need access to learning activities in their own language. If not, there is a large language barrier to adoption and a high probability that the learning activity results will be sub-optimal.

Employees often have multiple roles and responsibilities. It is hard for them to dedicate time and attention to learning for a long enough period to be effective and their company doesn't always support them in this. The company's focus is often on short term results while learning objectives are often longer term. Furthermore, companies are often not aware of the training needs of their employees. Determining these needs should be framed within the strategic objectives of the company.

Customised learning activities and e-learning content are expensive and as a consequence the more generic con- 
tent that is being delivered to the employees is often not fit to meet their needs. Companies, particularly SMEs that don't have a training responsible, want support in finding the adequate learning solutions matching their specific business and development needs. But there is not enough dialogue between e-learning providers and companies (E.C.-DG Education and Culture 2005).

Other reasons to reject e-learning include poor computer literacy, lack of personal access to computers with and without internet access, heavy workload, lack of motivation, low self-control.

\section{E-LEARNING READINESS AND MODELS TO MEASURE IT}

\section{A. E-learning readiness assessment and measurement models}

Literature on organisational readiness for e-learning provides managers with questions, guidelines, strategies, models and instruments for assessing the readiness of their companies. Aydin and Tasci [1] suggest a question tool with 7 categories: human resources, learning management system, learners, content, IT, finance and vendor. Another categorization results from Chapnic [4]: psychological, sociological, environmental, HR, financial readiness, technological skill (aptitude), equipment, content readiness.

When we examine closely the readiness models that can be found in literature, we see certain common parameters that always come back. Psycharis suggests three large categories [25]: resources, education and environment. Each category contains certain criteria. In the category resources, the technological readiness, the economic readiness and the human resources readiness are investigated. Education means the readiness of content and the training needs and preferences. Environment includes entrepreneurial readiness, leadership readiness and readiness of culture.

- Resources: First of all we want to investigate the technological readiness, the available technological systems that are provided and the way they are used. The economic readiness examines the willingness of the organisation to invest in e-learning. Implementing e-learning brings along large costs and the organisation needs to be prepared to make the necessary investments in infrastructure but also foresee a degree of administration support. The human readiness refers to the knowledge and the skills of the employees being the e-learners. An important question is whether staff has the necessary basic skills and whether they do feel at ease with used technology and with self-directed learning.

- Education: Whether or not an organisation is ready from an educational point of view will be determined by the measurement of the readiness of the content. Is the educational content easily available, is it well structured and is it reusable? But also the customisation of the content and training solutions to the specific business and development needs of the company and to user preferences is important. It is about the learning styles and the educational needs of the employees. The educational readiness ex-

amines the ability of the organisation to organize and implement an adequate educational program. Educational readiness is believed to be a particularly important factor. The availability of customised contents that can be implemented directly in the company are crucial to the adoption of e-learning.

- Environment: The criteria of this category are the entrepreneurial readiness (e-learning is considered to be a part of the organisation's strategy, and readiness depends on external factors such as the political and legal context or the company's interdependence) and the readiness of the culture, which examines the organisation's and the staff's (and the country's) behaviour and attitudes towards e-learning.

\section{B. Our e-learning readiness measurement instrument}

Studying the already existing theory and using our insights and quality aspects of e-learning, we developed an e-learning readiness measurement instrument. A self assessment questionnaire is to be built on it. This questionnaire can be slightly changed, and adapted to the sector in which it is used - if necessary.

We developed a questionnaire and used it to measure the e-learning readiness of the hospitals. We developed a set of questions based on our self assessment quality questionnaire [26]. Our instrument consists of enabling or delivery criteria and of results criteria (Figure 1). The enabling criteria relate to the creation of the environment in which e-learning can be implemented. They concern the preparation of the learners and the management of learning in the organisation.

The results criteria (Figure 2) refer to the level of preparedness to implement e-learning in the organisation. They can be used to assess the learner characteristics, the availability of technological facilities, the investments done by management and the quality of the e-learning solutions and processes themselves.

1.Enabling the employees/learners to participate in an e-learning course

- Assessment of learners competence

- Assessment of learners training needs and preferred learning style

- Motivating employees

- $\quad$ Organise and manage procedures and processes to share knowledge and experience in learning

- Optimise the learning process and the role of e-learning in it.

2.Training activity in the organisation is a management issue

- How training is valued in practice

- Time allocated to training

- Learning culture

- Evaluation of the impact of training

Figure 1. Enabling criteria of the E-learning readiness measurement model 


\begin{tabular}{|c|c|}
\hline $\begin{array}{l}\text { 1. Learner characteristics } \\
\text { - ICT skills of the learn- } \\
\text { ers } \\
\text { - Internet experience of } \\
\text { the learners } \\
\text { - Motivation for use of } \\
\text { e-learning of the trai- } \\
\text { nees } \\
\text { - Preferred learning } \\
\text { styles (prefer presenta- } \\
\text { tions including audio, } \\
\text { video,....) }\end{array}$ & $\begin{array}{l}\text { 3. Organisation and man- } \\
\text { agement of e-learning } \\
\text { - Willingness to invest in } \\
\text { physical environment, } \\
\text { good user systems and in } \\
\text { e-learning infrastructure } \\
\text { - Learning time during } \\
\text { working hours? } \\
\text { - Preparatory training in } \\
\text { usage computers and in- } \\
\text { ternet }\end{array}$ \\
\hline $\begin{array}{l}\text { 2. Availability of qualita- } \\
\text { tive technological facili- } \\
\text { ties for e-learning } \\
\text { - User ICT infrastructure } \\
\text { - Internet connectivity } \\
\text { - } \quad \text { Flexible Learning } \\
\text { management system to } \\
\text { handle web based ma- } \\
\text { terials } \\
\text { - System to connect } \\
\text { learners together } \\
\text { - Tracking the learning } \\
\text { activity }\end{array}$ & $\begin{array}{l}\text { 4. E-learning process and } \\
\text { solutions/ courses } \\
\text { Organisation of the e- } \\
\text { learning activity } \\
\text { Training in using e- } \\
\text { learning system } \\
\text { Support of the e- } \\
\text { learning activity/e- } \\
\text { coaching } \\
\text { Information about } \\
\text { available e-learning } \\
\text { courses } \\
\text { User friendly system } \\
\text { functions facilitating } \\
\text { learning activities } \\
\text { E-learning course con- } \\
\text { tent and presentation } \\
\text { Level of personalisation } \\
\text { of learning } \\
\text { Matching of course with } \\
\text { learning style } \\
\text { Matching of course with } \\
\text { job requirements }\end{array}$ \\
\hline
\end{tabular}

Figure 2. Result criteria of The E-learning readiness measurement model

\section{CASE AGFA HealthCARE: ApPlicAtion OF OUR} READINESS MEASUREMENT INSTRUMENT IN HOSPITALS

Agfa Healthcare is convinced of the advantages of using their e-learning solution for the hospitals, replacing the traditional classroom learning they offer now. But are the hospitals ready to change to an e-learning solution?

In collaboration with the company Agfa Healthcare, we used our e-readiness measurement instrument to investigate the e-learning readiness of 10 Flemish hospitals being the customers of Agfa.

We came to conclusions on the following e-readiness criteria: the required learner characteristics, the availability of qualitative technological facilities for e-learning, the organisation and management of e-learning, the e-learning processes and solutions/ courses, the possibilities given to the learners to participate in an e-learning course and the management issues about the training activity. The results of the questionnaire, which was surveyed in ten hospitals, were quite homogeneous. The following sections discuss the most valid results findings.

\section{A. Learner characteristics}

Most hospital employees don't have experience in using an e-learning course, although most of them work regularly with pc and have knowledge of the standard office packages. The learners are not more motivated for e-learning than for a traditional course. This can be explained by the fact that most of them so far don't have any experience with e-learning. It is an opportunity for the hospital management and for Agfa to clarify the advantages of an e-learning solution.

In point of the preferred learning styles, we see that video fragments are considered necessary in an e-learning course and the insertion of simulation modules in the elearning system are believed to create a large surplus value. However results also show that the hospital employees don't prefer audio above written documents.

\section{B. Availability of qualitative technological facilities for e-learning}

There are three distinct technological elements that organisations need to address if they are to be ready to deliver e-learning. These include the hardware available to staff, the internet connectivity and the flexibility of the system to engage with the existing web based material. In the reported case, employees seem to attach great importance to the physical conditions and these generally score well in Flemish hospitals.

We checked the expected ICT situation, the current situation and the implementation of the AGFA approach. A first remarkable result is the similarity between the expected situation of the hospitals and the solution for facilitating e-learning as delivered by AGFA. The results from AGFA can be considered to match very well the requirements in point of ICT infrastructure as formulated by the hospitals. We see a good match between the expected situation and the prospected situation by Agfa. However there seems to be a discrepancy between the expected situation and the actual situation. Hospitals are aware that the current situation of the ICT infrastructure is often not sufficient to meet the requirements. Additional investments are required.

We find another remarkable result with the underlying system functions to facilitate e-learning. There is a great discrepancy between the required underlying system functions (average score of 3.2) and the way Agfa wishes to facilitate them (average score of 1.0). Agfa has to consider building in more facilitating system functions.

Regarding the required elements for a collaborative elearning approach, we see that in the reported case those supporting system facilities are wanted by the hospitals but are not facilitated by the supplier. Here the opportunity to supply such facilities can be taken in order to increase the hospital's readiness.

In point of the maintenance of ICT facilities, an average score of 4.0 was obtained for the expected situation, which is remarkably higher than the average score of 2.5 of Agfa. This difference can be explained by the scores of the indicator "adjustment of the learning system to new versions of system software". Agfa should also consider the incorporation of this facility in the package. 


\section{Organisation and management of e-learning}

The wishes of all staff on this topic are quite similar to the ones concerning the physical aspects. The expectations are rather high, which is good in the case of Agfa since their physical learning environment is already at a high level. Spending the learning hours during working time is preferred to working at home. But the current ICT infrastructure isn't good enough in most cases. Hospital management is fairly prepared to make investments to upgrade to the necessary level in order to make e-learning possible and successful.

Since most employees don't have experience in using an e-learning course, although most of them work regularly with pc and have knowledge of the standard packages, guidance is required. It is very important that learners are guided the first time they engage in e-learning, and they prefer a classroom session organised in advance coaching them and enhancing the use of the system. It is recommendable that the key-users be thoroughly coached when they have no experience with e-learning.

\section{E-learning process and solutions/courses}

Regarding the availability of information on training material, all respondents agreed that the composition of the e-learning package must be made clear. Accordingly, Agfa can satisfy his customers by composing a clear overview of available e-learning solutions. We see a remarkable difference in the results between the demand by the hospital and the supply by Agfa in point of the personalisation of the e-learning courses. The hospitals want a reasonable customisation of the course in contrast with Agfa, who does not wish to incorporate this facility. However, by including the facility of customisation in their elearning solution, Agfa should contribute to the e-learning readiness of the hospitals.

We see a same gap in point of the "self management of the learning process". Agfa thinks this issue is very important in contrast with the hospitals that rate it low. All users in the hospital rate the aspect of supporting the learner in using the ICT infrastructure as well as in using the elearning system functions as important. Agfa considers this as being less important.

As to matching of learning contents with the learning styles and preferences of the learners, we identified the fact that video fragments are regarded necessary in an elearning course and the insertion of simulation modules in the e-learning system should create a large surplus value. Therefore, if those two items are integrated in the elearning course, the readiness of the users will increase.

\section{E. Enabling the employees/learners to participate in an e-learning course}

In the reported case, e-learning is not yet perceived as being more motivating than traditional learning. Therefore, the advantages of e-learning are to be well pointed out. A challenge for the Flemish hospitals is to convince their employees to participate in e-learning courses and to persist in it. We saw that the management of the hospitals believes in the added value of the implementation of elearning courses. The management is prepared to facilitate e-learning by the organisation of courses in ICT and internet usage for the employees/ learners. They are prepared to invest in new user ICT infrastructure.

\section{F. $\quad$ Training activity in the organisation is a management issue}

We focused our research on the Radiology department of the hospitals. The enlargement of knowledge of the used systems and the possibility of applying them in the department is straightforward. As a result, a profound knowledge of the systems is put forward by the head of the department.

The organisational learning culture or attitude to elearning in the hospitals is reflected in the learning environment it fosters, in the applicability of training on the job and in the way the organisation evaluates the impact of training. In the reported case we have not focused on this aspect, because we have only included in this research one department, relevant for this specific e-learning application.

\section{CONCLUSIONS}

E-learning is a good opportunity for companies to upskill their employees and meet the demands of lifelong learning but its implementation needs to be well prepared and managed because it brings about change in the organisation and often requires high investment costs. That is why it is important for a company to know if it is e-ready.

The article shows that e-readiness is a helpful measure for organisations to gain awareness of the conditions for successful e-learning and to evaluate their proper state-ofreadiness, allowing them to fully exploit the benefits of technology enhanced learning for their employees and to avoid/evaluate possible risk of failure.

The e-readiness measurement instrument we developed has already been tested in the healthcare sector. It seems to be very useful and customisable to other sectors. We used the instrument to conclude about the level of ereadiness of a sample of hospitals. The instrument can be used to measure the readiness of an individual company that plans to evolve to e-learning in the workplace.

\section{REFERENCES}

[1] Aydin, C.H. \& Tasci, D. (2005). Measuring readiness for elearning: reflections from an emerging country. Educational Technology \& Society, 8 (4), 244-257.

[2] Bernhardt et al., 2003: J.M.Bernhardt, C.W.Runyan, I.bou-saada and E.M.Felter: implementation and evaluation of a web-based continuing course in injury prevention and control. Health promotion Practice 4(2) (2003), pp 120-128. (doi:10.1177/1524 $\underline{839902250758)}$

[3] Bowles M. (2004): Relearning to e-learn: strategies for electronic learning and knowledge, Melbourne University Press.

[4] Chapnic,S. (2005). Are you ready for e-learning? Learning Circuits: ASTD's Online Magazine All about e-learning.

[5] Chorng-Shyong, Jung-Yu, Yi-Shun: Factors affecting engineers' acceptance of asynchronous e-learning systems in high-tech companies. Information \& management, Vol 41, Issue 6, 2004, pages 795-804.

[6] Ah-Choo Koo: Factors affecting teachers' perceived readiness for online collaborative learning: a case study in Malaysia. Educational Technology \& Society, 11 (1), 266-278.

[7] Claire Kenny, Claus Pahl (2008), 'Personalised correction, feedback and guidance in an automated tutoring system for skills training, International Journal of Knowledge and Learning (IJKL), Volume 4 - Issue 1, pp. 75 - 92

[8] Denise Ghanam, Philip Cox (2007), 'Dynamic capabilities: the strategy-HRM intersect?' , International Journal of Learning and Intellectual Capital (IJLIC), Volume 4 - Issue 1/2, pp. 57 - 74 
[9] Economist Intelligence Unit Limited and IBM Corporation (2003) The 2003 E-Readiness Rankings: A White Paper from the Economist Intelligence Unit 2003

[10] European Commission - DG Education and Culture (2005), Elearning in Continuing Vocational Training, particularly at the workplace, with emphasis on Small and Medium Enterprises, http://ec.europa.eu/education/programmes/elearning/doc/studies/v ocational educ en.pdf

[11] Ellis Maureen: Changing the face of traditional education: a framework for adapting a large, residential course to the web. Eleed journal 2007. (http://eleed.campussource.de/archive/ 3/1081/)

[12] H.B.Moolman, S.Blignaut: Get set! E-ready, ...e-learn! The ereadiness of warehouse workers. Technology \& Society, 11 (1), 168-182.

[13] K. Kaur, Abas, W. A. (2004) An assessment of e-learning readiness a the Open University Malaysia, International Conference on Computers in Education 2004

[14] Lytras M., Sicilia M. (2005) Knowledge Society a Manifesto for Knowledge and Learning, in International Journal of Knowledge and Learning, 1(1), pp: 1-11

[15] Mungania, P. The Seven E-Learning Barriers Facing Employees. The Masie Centre, 2003.

[16] E-Readiness in the Social Care Sector

[17] Miltiadis D. Lytras (2007) Teaching in the knowledge society: an art of passion, International Journal of Teaching and Case Studies (IJTCS), Volume 1 - Issue 1/2, pp. 1-9.

[18] Ozdemir Zafer and Abrevaya Jason: Adoption of technologymediated distance education: a longitudinal analysis. Information\& management Vol.44,issue 5, july 2007, pages 467-479

[19] Ozdemir Zafer, Altynkemer Kemal, Barron John: Adoption of Technology-mediated Learning in the USA. Decision Support Systems 2008.

[20] Peter Y.T. Sun, John L. Scott (2006), 'Process level integration of organisational learning, learning organisation and knowledge management' International Journal of Knowledge and Learning (IJKL), Volume 2 - Issue 3/4 - 2006, pp. 308 - 319

[21] Pfaus, B (2004) e-Learning Readiness: An international perspective. The e-learning developers' journal, Sept. 2004

[22] Piskurich, George M. (Ed.) (2003) Preparing Learners for Elearning. NY: John Wiley \& Sons Inc.

[23] Powell, G.C. (2000) Are you ready for web-based training? Educational Technology \& Society, 3 (1), 52-55.

[24] Ruikar, K., C.J. Anumba, P.M. Carrillo (2006) VERDICT - An ereadiness assessment application for construction companies, Automation in construction 15, 98-110. (doi:10.1016/j.autcon.2005. $\underline{02.009)}$
[25] Sarantos Psycharis ( 2005 ) Presumptions and actions affecting an e-learning adoptionby the educational system. Implementation using virtual private networks, Eurodl (http://www.eurodl.org/ materials/contrib/2005/Sarantos_Psycharis.htm)

[26] SCHREURS, Jeanne; Husson, A.M.; Merison, B.; Morin, E. \& Van Heysbroeck, H. (2008) SEVAQ: a unique multi-functional tool for assessing and improving the quality of e-courses. In: International Journal of emerging technologies in learning (iJET), 3(1).

[27] SCHREURS, Jeanne; Moreau Rachel; Dewever, Fanuel (2004): KMO's groeien naar het strategisch gebruik van het internet : de eadoptie. In: Staten-Generaal van de Limburgse economie en werkgelegenheid, p.111 - 131 .

[28] Shu Yu, I-Ju Chen, Kuei-Feng Yang, Tze-Fang Wang, Lee-Lan Yen: A feasibility study on the adoption of e-learning for public health nurse continuing education in Taiwan. Nurse Education today, Vol 27, Issue 7, 2007, pages 755-761.

[29] Singh, H. (2003) Building Effective Blended Learning Programs, November-December Issue of Educational Technology, Volume 43, Number 6, pp. 51-54.

[30] Snae, C. and Brueckner, M. Ontology-Driven E-Learning System Based on Roles and Activities for Thai Learning Environment. Interdisciplinary Journal of Knowledge and Learning Objects, Volume 3, 2007.

[31] Study from Ipsos MORI; Social Care Institute for excellence (SCIE). E-readiness in the social sector. December 2006. www.scie.org.uk/publications/consultation/readiness.pdf

\section{AUTHORS}

J. Schreurs (Jeanne.Schreurs@uhasselt.be) is Professor at the Faculteit Toegepaste Economische Wetenschappen, Universiteit Hasselt, Campus Diepenbeek, Agoralaan gebouw D, 3590 Diepenbeek, Belgium.

Anouk Gelan (anouk.gelan@uhasselt.be) is researcher at the Center of Applied Linguistics (CTL) of Hasselt University and is co-author of the e-learning modules "Plurilingua - Intercultural communication for (technical) managerial staff'. Hasselt University, Diepenbeek, Agoralaan gebouw D, 3590 Diepenbeek, Belgium

George Sammour (george.sammour@uhasselt.be) is a $\mathrm{PhD}$ student in Business Informatics at the Transportation Research Institute, Hasselt University, Diepenbeek, Agoralaan gebouw D, 3590 Diepenbeek, Belgium.

Manuscript received 28 April 2009. Published as submitted by the authors. 